\title{
PULMONER EMBOLİ HASTALARININ YOĞUN BAKIM TAKİBİ
}

\author{
Monitoring of Pulmonary Emboli Patients in Intensive Care Unit
}

\author{
Erdinç KOCA ${ }^{1}$
}

${ }^{1}$ Malatya Ĕgitim ve Araştırma Hastanesi, Anesteziyoloji ve Reanimasyon Kliniği, MALATYA, TÜRKIYE

Amaç: Pulmoner emboli yakın takip ve acil müdahale gerektiren ölümcül bir hastalıktır. Amacımız bu hastaların yoğun bakımımızdaki süreçlerini incelemektir.

Gereç ve Yöntemler: $\mathrm{Bu}$ çalışmada 26.12.2013 ile 01.01.2019 tarihleri arasında Anesteziyoloji ve Reanimasyon Yoğun Bakımda yatarak tedavi gören 37 pulmoner emboli hastası incelenmiştir. Hastaların yoğun bakım yatış süreleri, yaşı, tanıları, kan ihtiyacı, girişimler işlemleri, ekokardiyografik bulguları, pulmoner arterlerdeki trombüsün yerleşim yeri gibi parametreler incelenmiştir.

Bulgular: Hastaların \%27'si erkek, \%73'ü kadınlardan oluşmaktaydı. Hastaların yaş ortalaması 74 olarak tespit edildi. Yoğun bakımda tedavi gören ve pulmoner emboli tespit edilen 37 hastamızdan \%46's1 servise devredilerek daha sonra taburculuğu sağlanmıştır. Hastalara çekilen bilgisayarlı toraks anjiyografisinde trombüs yerleşiminin en s1k olarak sağ ana pulmoner arterde (\%38) olduğu görüldü.

Sonuç: Pulmoner emboli; erken tanı, hızlı tedavi gerektirebilen bir hastalıktır. Hastalar solunumsal ve kardiyak destek ihtiyacı duyabilir. 3. basamak yoğun bakımda takip edilen bu hastaların tedavi sürecinde aldıkları tedaviye rağmen ölüm oranlarının yüksek olması bu hastalığın mortalitesinin yüksekliği, ileri yaş ve eşlik eden hastalıkların varlığı ile açıklanabilir.

Anahtar Kelimeler: Yoğun bakım, pulmoner emboli, mortalite
Objective: Pulmonary embolism is a fatal disease that requires close follow-up and urgent intervention. Our aim is to examine the processes of these patients in our intensive care.

Material and Methods: This study examines the follow-up of 37 patients hospitalized with the diagnosis of pulmonary embolism in Anesthesiology and Reanimation Intensive Care between 26.12.2013 and 01.01.2019. In this study, parameters such as intensive care stay, age, diagnosis, blood transfusion requirement, invasive procedures, echocardiographic findings, location of the trombus in the pulmonary arteries were examined.

Results: Of the patients $27 \%$ were male and $73 \%$ were female. The average age of the patients was determined as 74 . Of the 37 patients who were diagnosed with pulmonary embolism and treated in intensive care, $46 \%$ were transferred to the service and later discharged. In the computerized thoracic angiography of the patients, it was seen that thrombus location (38\%) was mostly in the right main pulmonary artery.

Conclusion: Pulmonary embolism is a disease that may require early diagnosis and rapid treatment. Patients may need respiratory and cardiac support. The high mortality rates of these patients who are followed up in the tertiary intensive care unit despite the treatment they received during the treatment process can be explained by the high mortality of this disease, advanced age and the presence of accompanying diseases.

Keywords: Intensive care, pulmonary embolism, mortality 


\section{GíRiș}

Pulmoner emboli (PE), pulmoner arterlerin seyri boyunca herhangi bir k1smında, tam ya da kısmi olarak trombüs ile tıkanması olarak tanımlanır. T1kanmanın en s1k sebebi venlerde oluşan trombüsün koparak akciğerlere ulaşması ve burada tıkanıklığa sebep olmasıdır. Bu trombüslerin büyük bölümü alt ekstremite venlerinden kaynaklanır. Bu durum hayatı tehdit eden, ciddi bir sağlik problemidir. Acil müdahale gerektirebilen bu hastalığın tanınabilmesi için hastaların klinik, laboratuvar ve görüntüleme yöntemleriyle detaylı incelenmesi gereklidir (1-5). PE acil servislerde görülen ölüm nedenleri arasında 3. sıradadır. $\mathrm{Bu}$ hastalardan tanı alıp tedavi başlananlarda mortalitenin düştüğü bildirilmiştir. $\mathrm{Bu}$ hastaların yarıdan fazlasının tanısı otopsi esnasında konulmaktadır (6). PE, Amerika Birleşik Devletleri'nde yılda 300.000 ölüme neden olur (7). PE'de mortalite oranı \%30'un üzerindedir (8). Geliştirilen skorlama sistemleri, klinik çalışmalar ve teknolojik olanaklara rağmen PE tanısı kolaylıkla konulamamaktadır. İleri yaş, kardiyak ve solunumsal ek hastalık varlığı PE tanısının konulmasını zorlaştırır (9). Çalışmamızda, PE nedeniyle yoğun bakımda takip ettiğimiz olgularımızın verilerini literatür ışığında değerlendirerek bu hastaların yoğun bakım tedavilerinin sonuçlarını tartışmayı amaçladık.

\section{GEREÇ VE YÖNTEM}

$\mathrm{Bu}$ çalışmada, PE tanısı ile yoğun bakımda takibi yapılan hastaların, dosya kayıtları ve hastane hasta kayıt bilgi sistemi üzerindeki bilgileri geriye dönük taranarak değerlendirilmiştir. $\mathrm{Bu}$ çalışma 36 yataklı Malatya Eğitim ve Araştırma Hastanesi Anesteziyoloji ve Reanimasyon Yoğun Bakım ünitesinde yapılmıştır. Çalışmaya 26.12.2013 ile 01.01.2019 tarihleri arasında yoğun bakımda takip edilen 37 hasta dahil edilmiştir. Bu çalışmada hastaların yaşı, tanısı, yoğun bakım yatış süresi, vazopressör ihtiyac1, ventilasyon ihtiyac1, entübasyon, intra-arteriyal kanülasyon, santral venöz kateterizasyon, kan ihtiyacı, taze donmuş plazma ihtiyac1, albumin ihtiyac1, verilen tedaviler, ekokardiyografik (EKO) bulgular, pulmoner arterlerdeki trombüsün yerleşim yeri, derin venöz trombüs varlığı, kardiyovasküler resüsitasyon ve sonuçları kaydedilmiştir.

\section{İstatistiksel Analiz}

Sonuçları ve demografik verileri tanımlamak için SPSS Statistics 22 programı kullanılarak descriptive istatistik analizi (betimleyici istatistik analizi) yapıldı.

\section{BULGULAR}

Malatya Eğitim ve Araştırma Hastanesi 718 sayılı bilimsel kurul izni ve Malatya Klinik Araştırmalar Etik Kurulu'ndan (Tarih: 03.02.2021, sayı no: 2021/49) etik kurul izni alındı. Hastane bilgi işlem sistem kayıtları ve hasta dosyaları retrospektif olarak incelenmiştir. Takip edilen hastaların yaş ortalaması 74 (35-95) idi. Hastaların 10'u erkek, 27'si kadın idi (Tablo 1). Yoğun bakımda takip edilen hastaların ek hastalıkları Tablo 2 'de gösterilmiştir. Hastaların tanıları incelendiğinde en sık olarak \%27 oranında kronik obstrüktif akciğer hastalığı (KOAH) olduğu görülmüştür (Tablo 2). PE açısından risk oluşturan durumlar açısından hastalarımıza bakıldığında \%6 oranında alt ekstremite cerrahisi sonrası PE oluştuğu görülmüştür (Tablo 2).

Tablo 1: Demografik veriler

\begin{tabular}{lcc}
\hline & $\mathbf{n} / \%$ & Yaş ortalama standart sapma \\
\hline Erkek & $10 / 27$ & $67.9 \pm 13.4$ \\
Kadın & $27 / 73$ & $76.5 \pm 15.4$ \\
Toplam & $37 / 100$ & $74 \pm 15.2$ \\
\hline
\end{tabular}

Hastalara yoğun bakımda tedavileri boyunca invaziv girişimler yapılmıştır. $\mathrm{Bu}$ işlemlerden en çok yer alan endotrakeal entübasyon ve mekanik ventilatör ile 
takipdir. Ayrıca 2 hastaya uzamış entübasyondan dolayı trakeostomi açılmıştır (Tablo 2).

Tablo 2: Klinik bulgular, girişimler, tedaviler ve sonuçlar

\begin{tabular}{|c|c|}
\hline $\begin{array}{l}\text { Hastaların yoğun bakıma kabulde } \\
\text { mevcut ek hastalıkları }\end{array}$ & $\mathrm{n} / \%$ \\
\hline Hipertansiyon & $9 / 24$ \\
\hline Diyabet & $3 / 8$ \\
\hline Kalp yetmezliği & $9 / 24$ \\
\hline Koroner arter hastalığ 1 & $2 / 5$ \\
\hline КOAH & $10 / 27$ \\
\hline Astım & $1 / 3$ \\
\hline SVO & $3 / 8$ \\
\hline Akut Böbrek Yetmezliği & $1 / 3$ \\
\hline $\begin{array}{l}\text { PE için risk oluşturan hastalıklar ve } \\
\text { tedaviler }\end{array}$ & \\
\hline Geçirilmiş alt ekstremite cerrahisi & $6 / 16$ \\
\hline Malignite & $3 / 8$ \\
\hline Bilinen derin ven trombozu & $4 / 10$ \\
\hline Oral kontraseptif kullanımı & $1 / 3$ \\
\hline Atriyel fibrilasyon & $2 / 5$ \\
\hline $\begin{array}{l}\text { Yoğun bakımda yapılan girişimler ve } \\
\text { tedaviler }\end{array}$ & \\
\hline Entübasyon & $14 / 38$ \\
\hline Mekanik ventilasyon & $21 / 56$ \\
\hline Santral venöz kateter & $17 / 45$ \\
\hline İnraarteryal kateter & $28 / 76$ \\
\hline Kan transfüzyonu & $11 / 30$ \\
\hline Taze donmuş plazma replasmanı & $4 / 11$ \\
\hline Vazopressör kulanımı & $18 / 49$ \\
\hline Albumin ihtiyacı & $2 / 5$ \\
\hline Kardiyopulmoner resüsitasyon & $20 / 54$ \\
\hline Trakeostomi & $2 / 5$ \\
\hline \multicolumn{2}{|l|}{$\begin{array}{l}\text { Hastaların } \\
\text { tedaviler }\end{array}$} \\
\hline Standart heparin & $1 / 2$ \\
\hline
\end{tabular}

\begin{tabular}{lc}
\hline Düşük molekül ağırlıklı heparin & 37 / 100 \\
Trombolitik & $7 / 19$ \\
Kumadin & 2 / 5 \\
Asetilsalisilik asit & $4 / 11$
\end{tabular}

\begin{tabular}{ll}
\hline Alt ekstremite dopler DVT ve EKO’da sağ & \\
ventrikül işlev bozukluğu oranları & \\
Alt ekstremite dopler DVT & $12 / 32$ \\
EKO'da sağ ventrikül işlev boz. & $28 / 76$
\end{tabular}

Bilgisayarlı toraks anjiyografide (BTA)
trombüs tespit edilen arter

Pulmoner trunkus

Sağ ana pulmoner arter

Sol ana pulmoner arter

$10 / 27$

Sağ alt lober arter

Sol alt lober arter

Sağ üst lober arter

Sol üst lober arter

Sağ pulmoner arterde segment düzeyi

Sol pulmoner arterde segment düzeyi

$1 / 3$

Hastaların Surveyleri

Servise nakil

$17 / 46$

Exitus

$20 / 54$

Yoğun bakıma yatırılan tüm hastalarımızda dispne şikâyeti olduğu görüldü. Hastalarımızın 7'si entübe kabul edilirken, 2'si kabul edildikten hemen sonra entübe edilmiştir. Ayrıca 14 hastada takipne, 20 hastada hipotansiyon, 18 hastada taşikardi olduğu görüldü. Hastalarımız D-dimer değerleri incelendiğinde (kit normal sınır 0-0.5) ortalama 6.3 olduğu görüldü. Yoğun Bakım Yatış Süreleri değerlendirildiğinde ortalama 7.64 gün olduğu ve en uzun yatış süresinin ise 24 gün olduğu görüldü (Tablo 3). Hastaların APACHE skorları değerlendirildiğinde yaşayanların ortalaması 19.8 ölenlerin ise 24.4 olarak tespit edildi (Tablo 4). Hastaların tedavileri değerlendirildiğinde tüm hastaların Düşük Molekül Ağırlıklı Heparin aldığı görüldü. Sadece 7 hastaya trombolitik tedavi verilmiş ve bu hastalardan 4’ü ölmüştür (Tablo 2). Alt Ekstremite Doplerde Derin 
venöz tromboz \%32 oranında olduğu, EKO’da ise \%76 oranında sağ ventrikül işlev bozukluğu olduğu görüldü (Tablo 2). Hastaların pulmoner arter görüntülemesinde trombüs yerleşiminin \%38 oranında en s1k olarak sağ ana pulmoner arterde olduğu görüldü (Tablo 2). Hastalar klinik tanımlamaya göre 18'i (\%48.6) masif tromboemboli, 10'u (\%27) submasif tromboemboli, 9'u $(\% 24.4)$ nonmasif tromboemboli olarak siniflandirıldi. Hastaların \%54'ü yoğun bakım tedavileri esnasında ölmüşlerdir (Tablo 2).

Tablo 3: Yoğun bakım yatış süreleri

\begin{tabular}{lc}
\hline & Gün \\
\hline Yoğun bakım yatış süresi & 283 \\
Ortalama & 7.64 \\
Aralık & $2-24$ \\
\hline
\end{tabular}

Tablo 4: Yaşayan ve yaşamayan hastaların APACHE skorlar1.

\begin{tabular}{|c|c|c|c|}
\hline & $\begin{array}{c}\text { Yaşayan } \\
\text { ort }\end{array}$ & $\begin{array}{c}\text { Yaşamayan } \\
\text { ort }\end{array}$ & $\begin{array}{c}\text { Toplam } \\
\text { ort }\end{array}$ \\
\hline Yaş & 73.3 & 75 & 74 \\
\hline APACHE & 19.8 & 24.4 & 22.3 \\
\hline $\begin{array}{l}\text { APACHE } \\
\text { Evaluation) }\end{array}$ & e Phy & $\mathrm{y}$ and Chr & ic Health \\
\hline
\end{tabular}

\section{TARTIŞMA}

PE, ani başlayan solunum sıkıntısı, takipne, taşikardi ve göğüs ağrısı ile karakterizedir. PE semptomları birçok hastalıkla karışabildiğinden tanı kolaylıkla konulamamaktadır. Masif embolilerde önde gelen semptom solunum sıkıntısıdır. Bizim de yoğun bakıma kabul ettiğimiz hastalarda da önde gelen semptom dispne olarak tespit edildi. Masif embolilerde solunum sıkıntısına plöritik tarzda göğüs ağrısıda eşlik eder (10). Masif PE'lilerde hipotansiyon, taşikardi, ciddi hipoksemi birlikteliği mortalitenin yüksekliğine işaret eder. $\mathrm{Bu}$ şok tablosu ile başvuran hastaların mortalite oranı \%52-65 arasındadır (11). PE Amerika Birleşik Devletlerindeki ölüm sebepleri içinde üçüncü sıradadır (12). 52208 PE hastasında yapılan çalışmada hastaların yaş ortalaması 61.7 yıl bulunmuştur. $\mathrm{Bu}$ hastaların \%56'sının kadın hasta olduğu görülmüştür (13). Bizim hasta grubumuzda yaş ortalaması 74 olarak tespit edildi. PE'de erken mortalite ile ilgili güncel rehberler uyarılarda bulunmaktadır. Özellikle embolinin ilk saatlerinde mortalitenin daha yüksek olduğu bildirilmiştir (14). Özellikle akut PE'de yineleyen emboliler büyük pulmoner arterlerinde tıkanmasına neden olarak ölümcül sonuçlar doğurmaktadır (15).

PE'nin mortalitesinin yüksek olmasından dolayı erken tanı ve hızlı tedavi prognoz açısından önemlidir. Hastalarda ileri yaş, obezite, geçirilmiş cerrahiler özellikle alt ekstremite cerrahileri, kalp hastalıkları, kanserler, hareket kısıtlılığı oluşturan hastalıklar derin ven trombozuna yatkınlık oluşturarak PE için risk teşkil etmektedir. Ayrica PE'nin kardiyak etkileri hayati risk oluşturur. Sağ ventrikül disfonksiyonu, pulmoner arterde meydan gelen tıkanıklığa sekonder sağ ventrikul ard yükünde artma ve pulmoner arter basıncında ani yükselme sonucunda ortaya çıkar. Masif PE'lilerde hipotansiyon, şok, ciddi hipoksemi, dispne, göğüs ağrısı ve siyanoz gelişir. $\mathrm{Bu}$ tablodaki hastalarda mortalite yüksektir. EKO sağ ventrikul sistolik fonksiyonunu değerlendirmek için kullanılır. Sağ ventrikül disfonksiyonu hastalığın kötü klinik seyri açısından bağımsız risk faktörüdür (16).

Avrupa Kardiyoloji Derneği (European Society of Cardiology, ESC) 2014 yılında yayınladığı rehbere göre klinik olarak PE tanısı düşünülen hastada, klinik olarak hipotansiyon ve şok durumuda mevcutsa, PE tanısı EKO bulgularına dayanılarak konur ve reperfüzyon tedavisi verilebilir (16). Hastalarımıza EKO yapılarak kardiyak fonksiyonlar değerlendirilmiş ve \%76 hastada sağ ventrikül sistolik disfonksiyonu tespit edilmiştir. ICOPER (International Cooperative Pulmonary Embolism Registry-Uluslararası Pulmoner Emboli 
Kayıt Birliği) çalışmasında hastalar hemodinamik verilerine göre değerlendirilmiş ve hemodinamik olarak stabil olan hastalarda mortalite \%15.1 iken, hemodinamik olarak stabil olmayan (hipotansiyon, şok bulgular1) hastalarda mortalite \%58.3 olarak tespit edilmiştir. Bizim hastalarımızın mortalite oranı ise \%54 olarak tespit edilmiştir. Yoğun bakım ihtiyacı olan bu hasta grubundaki oran litaratürle pareleldir. Ayrıca bu çalışmada, mortalite açısından hemodinamik stabilitenin en belirleyici faktör olduğu belirtilmiştir (17).

Klinik olarak PE düşünülen hastalarda ilk olarak bir fibrin yıkım ürünü olan D-dimer testi bakılır. Bu testin yüksekliği birçok durumda olsa da PE için önemli belirleyicilerdendir. Bizim hastalarımızda D-dimer değerleri incelendiğinde ortalama değerin 6.3 (kit üst sınırı 0.5) olduğu görüldü. Bu tetkik yaşa bağlı olarak üst sınırı yükseldiği dikkate alınarak değerlendirilmelidir $(18,19)$. D-dimer testinin negatif sonuç vermesi venöz tromboemboli tanısını \%95 oranında ekarte ettirebilir. Bundan dolayı yoğun bakım ünitelerindeki hastalarda venöz tromboemboli şüphesinde oldukça yaralıdır (20). PE tanısında alt ekstremite Doppler Ultrasonografide (DUSG) Derin Ven Trombozu (DVT) saptanması, klinik bulgular ve pozitif D-dimer varlığı tanıda önemli yer kaplar (21). PE tanısı konulan hastalarda DVT saptanma oranı \%37 oranında olduğu bildirilmiştir (22). DVT açısından hastalarımıza alt ekstremite dopler ultrasonografi yapılmış ve hastalarımızın \%32'sinde DVT belirlenmiştir.

PE tanısının konulmasında Bilgisayarlı Toraks Anjiyografi (BTA) altın standart yöntem olarak kabul edilmektedir (23). Gelişen teknolojiler ve Spiral BT PE'lerin noninvaziv tanısında oldukça önemlidir. Yapılan çalışmalar santral PE'lerin tanısında BT'nin duyarlılık ve özgüllügünün \%90’’n üstünde olduğu ortaya konmaktadır (24). Wouter ve ark. PE tanısı alan 487 hasta üzerinde yaptıkları çalışmada embolinin yerini en sık \%28.5 oranında lober arterlerde olduğunu saptamışlardır (25). Şen ve ark. yaptıkları çalışmada PE tanısı konulan hastalarda embolinin en sık yerleştiği yerin sağ alt lober arter olduğunu bildirmişlerdir (26). Duru ve ark. 205 PE hastasını incelemiş ve bu hastaların 117 'sinde (\%57) embolinin en sık bulunduğu yerin sağ ve sol lober arterler olduğunu tespit etmişlerdir. (27). Olgularımızda BTA'de trombüsün pulmoner arterlerde bulundukları yerler açısından değerlendirildiğinde literatürle benzer olarak en sık sağ ana pulmoner arterde olduğu tespit edilmiştir.

PE'ye bağlı gelişen ciddi hipoksemi hastalara oksijen desteği vermeyi gerektirir. Yüksek akımlı oksijen tedavisi veya non invaziv mekanik ventilasyon (NIMV) ilk tercih olarak kullanılır. Fakat invaziv mekanik ventilasyon (İMV) tedavisi gerektiren hastalarda invaziv ventilasyona bağlı artmış intratorasik basınç venöz dönüşü bozarak tabloyu daha da kötüleştirebilir. Sağ ventrikül yetmezliği olan bu hastalarda basınçlar düşük tutulmalı ve düşük tidal volüm ayarlanmalıdır (28). Tedavi seçenekleri içinde oksijen tedavisi, ventilasyon, vazopressör ilaçlar, inhale nitrik oksit, akut sağ ventrikül yetmezliğinin farmakolojik tedavisi, Ekstrakorporal membran oksijenizasyonu (ECMO) ileri kardiyak yaşam desteği, parenteral antikoagülasyon, sistemik trombolitik tedavi, perkütan kateter aracılı embolektomi ve cerrahi embolektomi vardır (16). PE antikoagülan ilaçlar tedavide ilk seçenektir. Masif emboli ve sağ kalp yetmezliği olan hastalarda trombolitik tedavide tercih edilebilir. DMAH rekürensin önlenmesinde tercih edilen ajandır (29). 612 PE hastasında yapılan çalışmada tekrarlayan venöz tromboembolizm ve ölüm oranları açısından standart heparin ile düşük molekül ağırlıklı heparin tedavisi karşılaştırılmış ve bir fark bulunamamıştır (29). Trombolitik tedavi PE'de önemli bir tedavi seçeneğidir. Periferik venöz yolla iki saatte verilen $100 \mathrm{mg}$ alteplaz önerilen tedavi rejimidir (30). PE'de trombolitik tedavi rejimi $100 \mathrm{mg} / 2$ saat infuzyon veya 50mg/1 saat şeklinde önerilmektedir (31). PE nedeniyle kardiyak arrest olan hastada alteplase dozu:50 mg/2-5 dakika sürede verilir, infüzyon esnasında 
kardiyopulmoner resüsitasyona (KPR) devam edilmelidir (32). Trombolitik tedavi, yapısal intrakranial hastalıklar, yeni geçirilmiş beyin ameliyatları veya spinal cerrahiler, geçirilmiş intrakranial kanama, beyin hasarına neden olan kafa travma öyküsü, son üç ay içinde geçirilmiş inme, aktif kanama veya kanama diyatezi varlığında kontrendikedir (16). Avrupa Resüsitasyon Konseyi 2015 yılında yayınlamış olduğu kılavuzda pulmoner embolinin neden olduğu kardiyak arrestlerde trombolitik tedavi önermiştir (33). Alirızaoğlu ve ark. masif PE nedeniyle kardiyopulmoner arrest olan iki vakada trombolitik tedavi vermişlerdir ve bu iki hastaya uygulanan KPR başarıya ulaşmıştır. Hastalarımız klinik tanımlamaya göre değerlendirildiğinde $\quad 18^{\prime}$ 'inde $\quad(\% 48.6) \quad$ masif tromboemboli, 10'unda (\%27) submasif tromboemboli olduğu görüldü. Bizim 7 hastamıza trombolitik tedavi uygulanmış ve bu hastalardan 3'ü yoğun bakımdan taburcu edilmiştir (34). Trombolitik tedavi verilmesi kontrendike olan hastalarda girişimsel kateterizasyon teknikleri ile embolektomi veya cerrahi pulmoner embolektomi önerilir (35).

PE sık olarak görülmektedir. Birçok olgu otopsi sırasında tanınmaktadır. Yoğun bakımda PE nedeniyle tedavi gören hastaların yakın monitörizasyon ve s1k1 takibi gereklidir. Özellikle yoğun bakımda noninvaziv, invaziv solunum desteği ihtiyacı olan hemodinamik açıdan stabil olmayan hastalarda kontrendikasyon yoksa öncelikli olarak trombolitik tedavi verilmesi kanısındayız.

Destek / Teşekkür Beyanı: Herhangi bir mali destek alınmamıştır.

Etik Kurul Onamı: Malatya Klinik Araştırmalar Etik Kurulu; tarih: 03.02.2021, sayı no: 2021/49.

\section{KAYNAKLAR}

1. Alikhan R, Peters F, Wilmott R, Cohen AT. Fatal pulmonary embolism in hospitalised patients: a necropsy review. J Clin Pathol. 2004;57(12):1254-7.

2. Heit JA, O'Fallon WM, Petterson TM, Lohse CM, Silverstein MD, Mohr DN et al. Relative impact of risk factors for deep vein thrombosis and pulmonary embolism: a population-based study. Arch Intern Med. 2002;162(11):1245-8.

3. Palevsky HL, Kelly MA, Fishman AP. Pulmonary thromboembolic disease. In: Fishman AP, ed. Fishman's Pulmonary Diseases and Disorders. 3rd ed. New York. Mc Graw-Hill, 1998;1297-329.

4. Wagenvoort CA. Pathology of pulmonary thromboembolism. Chest. 1995;107(1):10-7.

5. Saygıner A. Akciğer embolizmi. In: İliçin G, Ünal S, Biberoğlu K, Akalın S, Süleymanlar G, eds. Temel İç Hastalıkları. Ankara. Güneş Tıp Kitabevi, 1996;538-43.

6. Morgenthaler TI, Ryu JH. Clinical characteristics of fatal pulmonary embolism in a referral hospital. Mayo Clin Proc. 1995;70(5):417-24.

7. Wendelboe AM, Raskob GE. Global burden of thrombosis: epidemiologic aspects. Circ Res. 2016;118(9):1340-7.

8. Harold I, Mark A. Pulmonary thromboembolic disease. In: Fishman AP, ed. Pulmonary Disease and Disorders. Newyork. Mc Graw-Hill Book Company, 1998;1297-329.

9. Guintini C, Di Rocco G, Marini C, Melillo E, Palla A. Pulmonary embolism: Epidemiology. Chest. 1995;107:3-9.

10. Manganelli D, Polla A, Donnamaria V. Clinical features of pulmonary embolism. Chest. $1995 ; 107(1): 25-32$

11. Sakuma M, Nakamura M, Nakanishi N, Miyahara Y, Tanabe N, Yamada N et al. Inferior vena cava filter is a new additional therapeutic option to reduce 
mortality from acute pulmonary embolism. Circ J. 2004;68(9):816-8.

12. The Surgeon General's Call to Action to Prevent Deep Vein Thrombosis and Pulmonary Embolism. Accessed date: 17.08.2021:

www.ncbi.nlm.nih.gov/books/NBK44178/.

13. Silverstein MD, Heit JA, Moher DN, Petterson TM, O'Fallon WM, Melton LJ et al. Trends in the incidence of deep vein thrombosis and pulmonary embolism: A 25-year population based study. Arch Intern Med. 1998;158(6):585-93.

14. Torbicki A, Perrier A, Konstantinides S, Agnelli G, Galie N, Pruszczyk $P$ et al. Guidelines on the diagnosis and management of acute pulmonary embolism of the European Society of Cardiology (ESC). Eur Heart J. 2008;29(18):2276-315.

15. Golbaşı Z. Chronic thromboembolic pulmonary hypertension: diagnosis, medical therapy and monitoring. Anadolu Kardiyol Derg. 2010;10(2):5660.

16. Konstantinides SV, Torbicki A, Agnelli G, Danchin N, Fitzmaurice D, Galiè N et al. ESC guidelines on the diagnosis and management of acute pulmonary embolism. Eur Heart J. 2014;35(43):3033-69.

17. Goldhaber SZ, Visani L, De Rosa M. Acute pulmonary embolism: clinical outcomes in the International Cooperative Pulmonary Embolism Registry (ICOPER). Lancet. 1999;353(9162):13869.

18. Kabrhel C, Mark Courtney D, Camargo CA, Moore CL, Richman PB, Plewa MC et al. Potential impact of adjusting the threshold of the quantitative Ddimer based on pretest probability of acute pulmonary embolism. Acad Emerg Med. 2009;16(4):325-32.

19. Becattini C, Lignani A, Masotti L, Forte MB, Agnelli G. D-dimer for risk stratification in patients with acute pulmonary embolism. J Thromb Thrombolysis. 2012;33(1):48-57.
20. Kollef MH, Zahid M, Eisenberg PR. Predictive value of rapid semiquantative D-dimer assay in critically ill patients with suspected venous thromboembolic disease. Crit Care Med. 2000;28(2):414-20.

21. Kostrubiec M, Labyk A, Pedowska-Wloszek J, S Pacho, A Wojciechowski, K Jankowski et al. Assessment of renal dysfunction improves troponinbased shortterm prognosis in patients with acute symptomatic pulmonary embolism. J Thromb Haemost. 2010;8(4):654-58.

22. Ozbudak O, Erogullari I, Oğuz C, Cilli A, Turkay M, Ozdemir T. Doppler ultrasonography versus venography in the detection of deep vein thormbosis in patients with pulmonary embolism. J Thromb Trombolysis. 2006;21(2):159-62.

23. Van Belle A, Buller HR, Huisman MV, Huisman PM, Kaasjager K, Kamphuisen PW et al. Effectiveness of managing suspected pulmonary embolism using an algorithm combining clinical probability, D-dimer testing, and computed tomography. JAMA. 2006;295(2):172-9.

24. Naidich DP, Zerhouni EA, Müller NL, Webb WR, Krinsky GA, Siegelman SS. Computed tomography and magnetic resonance of the thorax. 3rd ed. New York. Lippincott-Raven, 1999.

25. De Monye W, van Strijen MJ, Huisman MV, Kieft GJ, Pattynama PM. Suspected pulmonary embolism: Prevalence and anatomic distribution in 487 consecutive patients. Advances in new technologies evaluating the localisation of pulmonary embolism (ANTELOPE) group. Radiology. 2000;215(1):1848 .

26. Şen E, Arslan F, Eladağ Yurt S, Tarakcı N, Kaya A, Atasoy C ve ark. Pulmoner bilgisayarlı tomografi anjiyografi ile pulmoner tromboemboli tanıs konulan hastalarda klinik ve radyolojik bulgular. Tuberkuloz ve Toraks Dergisi. 2009;57(1):5-13.

27. Duru S, Ergün R, Dilli A, Kaplan T, Kaplan B, Ardıç S. Pulmoner embolide klinik, laboratuvar ve KÜTFD | 268 
bilgisayarlı tomografi pulmoner anjiyografi sonuçları: 205 hastanın retrospektif değerlendirmesi. Anadolu Kardiyol Derg. 2012;12(1):142-9.

28. Messika J, Goutorbe P, Hajage D, Ricard JD. Severe pulmonary embolism managed with high-flow nasal cannula oxygen therapy. Eur J Emerg Med. 2017;24(3):230-2.

29. THESEE study group. A comparison of lowmolecular weight heparin with unfractioned heparin for acute pulmonary embolism. N Engl J Med. 1997;337(10):663-9.

30. Uçar EY. Thrombolitic treatment. Türkiye Klinikleri J Pulm Med-Special Topics. 2016;9:39-43.

31. Hasanoglu HC, Hezer H, Karalezli A, Arguder E, Kilic H, Sentürk A et al. Half dose recombinant tissue plasminogen activatortreatment in venous thromboembolism. J Investig Med. 2014;62(1):71-7.

32. Sharifi M, Berger J, Beeston P, Bay C, Vajo Z, Javadpoor S. Pulseless electrical activity in pulmonary embolism treated with thrombolysis (From the "PEAPETT" Study). Am J Emerg Med. 2016;34(10):1963-7.

33. Truhlář A, Deakin CD, Soar J, Khalifa GE, Alfonzo A, Bierens JJ et al. European Resuscitation Council Guidelines for Resuscitation 2015: Section 4. Cardiac arrest in special circumstances. Resuscitation. 2015;95:148-201.

34. Alizoroğlu D, Erbaycu A E, Çimen P, Ediboğlu Ö, Kıraklı C. Kardiyopulmoner arrest gelişen masif pulmoner embolide trombolitik kullanımı: hayata dönen iki hasta. Turk J Intensive Care. 2019;17:1026.

35. Vishal S, Mehta N, Rawat N, Lehrman SG, Aronow WS. Management of massive and nonmassive pulmonary embolism. Arch Med Sci. 2012;6:95769. 